Quen Mok Ruth Gilbert

\section{Interventions to reduce central venous catheter-associated infections in children: which ones are beneficial?}

Received: 24 December 2010

Accepted: 9 January 2011

Published online: 27 January 2011

(C) Copyright jointly held by Springer and ESICM 2011

This editorial refers to the article available at: doi:10.1007/s00134-010-2116-x.

Q. Mok ( )

Paediatric Intensive Care Unit,

Great Ormond Street Hospital for Children,

London, UK

e-mail: mokq@gosh.nhs.uk

Q. Mok

Portex Unit of Paediatric Critical Care,

UCL Institute of Child Health, London, UK

R. Gilbert

Centre for Evidence-Based Child Health,

MRC Centre of Epidemiology for Child Health,

UCL Institute of Child Health, London, UK

Each year an estimated quarter of a million central venous catheters (CVC) are inserted in England and 5 million in the USA $[1,2]$. CVCs are important for monitoring, drug delivery, intravenous feeding and blood sampling for patients receiving critical care. They are also a common cause of hospital-acquired bloodstream infection and hence a major cause of morbidity, mortality and increased healthcare costs. The National Audit Office in the UK suggested that approximately $44 \%$ of hospital-acquired bacteraemias were associated with invasive devices, with nearly two-thirds of these related to CVCs [3]. Both adult and paediatric intensive care units (PICUs) have among the highest rates of hospital-acquired bacteraemia of all specialities, with each infection costing an estimated additional US \$40,000-46,133 [4]. As many of these infections are preventable, catheter acquired bloodstream infection (CA-BSI) has become a major issue for assessing the quality of care in intensive care units on both sides of the Atlantic [5-7].

Recent quality improvement initiatives have dramatically reduced rates of CA-BSI. Bundles of care, involving multifaceted interventions to improve CVC care and monitor adherence to recommendations, have been successfully introduced across North America and the UK [5, $6,8,9]$. CVC bundles address two main mechanisms of infection. Firstly, they reduce contamination from skin commensals during CVC insertion. Bundles typically recommend strict hand-washing, cleaning the skin with $2 \%$ chlorhexidine and allowing $30 \mathrm{~s}$ for drying, maximal barrier methods, and avoidance of the femoral vein. Secondly, they reduce accumulation of organisms in the CVC lumen, by reducing contamination during sampling or infusion. CVC maintenance bundles include recommendations for minimising the duration of CVC insertion, improving catheter site care, and cleaning the hub with $2 \%$ chlorhexidine when sampling and changing infusion sets [5-7]. Use of CVCs impregnated with antibiotics or heparin is another way of reducing bacterial adherence to the CVC lumen, but these are not recommended in the USA or UK unless infection rates remain high despite implementation of the CVC bundles [7, 10].

The success of CVC bundles has been measured by studies comparing CA-BSI rates before and after their introduction: there have been no randomised controlled trials of the effectiveness of CVC bundles. Pronovost et al. [11] showed a two-thirds reduction in CA-BSI rates, which, in 108 adult ICUs, was sustained for 36 months. The CVC bundle focussed on improved CVC insertion guidelines and reducing the duration of $\mathrm{CVC}$ insertion. Similarly large reductions have been seen in PICUs, but there is growing evidence that success depends on interventions that prevent 
accumulation of organisms after CVC insertion. Improvements in CVC insertion are not sufficient. In a before-after study in 29 PICUs, Miller [5] reported that maintenance bundle compliance was the only significant predictor of reduced CA-BSI rates. In another US study of a planned series of interventions, Bhutta et al. [9] saw no change after introducing maximal barrier methods for CVC insertion, but a step reduction in CA-BSI when antibiotic-impregnated CVCs were introduced. Further evidence for the importance of reducing risk factors throughout the duration of CVC in children, not just at insertion, is reported in this issue of Intensive Care Medicine by Rey et al. [12] They found that the CR-BSI rate fell from 12/1,000 CVC days to $3 / 1,000$, after they halved the proportion of children receiving total parenteral nutrition and reduced the duration of CVC insertion by $20 \%$.

There are several reasons why children may be more at risk than adults of accumulating organisms after CVC insertion, making bundles for maintaining CVC sterility relatively more important. First, the case mix is different with a higher number of children who are immunocompromised and have congenital abnormalities. Secondly, children have small veins, which are susceptible to thrombosis, thus increasing bacterial adhesion [13, 14]. Thirdly, although femoral venous catheterization is associated with a greater risk of infective and thrombotic complications $[15,16]$, the femoral vein is safer and more commonly used as a site for CVCs in children. Fourthly, CVCs may be accessed more frequently for blood sampling to avoid traumatising the child and to preserve peripheral veins. For the same reason, CVCs are more precious in children than in adults and less likely to be replaced unless blocked or clearly infected. Fifth, children are more likely than adults to receive total parenteral nutrition, which increases the risk of CA-BSI [12-14, 17].

This constellation of risk factors begs the question of whether the effectiveness of CVC maintenance bundles could be improved by including impregnated CVCs, especially for children who need a CVC for more than 2-3 days. This question is being addressed by a large randomised controlled trial involving 1,200 children in 11 of the 24 PICUs in the UK - the CATheter infections in CHildren (CATCH) trial, funded by the UK National Institute of Health Research. The primary aim is to compare the effect of impregnated with standard CVCs on any bloodstream infection, in the context of widespread implementation of CVC bundles. Both antibiotic-impregnated and heparin- bonded CVCs are being compared with standard CVCs as it remains unclear whether they are more effective than standard CVCs for all-cause BSI and which type is best. A systematic review of impregnated catheters reported significant and substantial reductions in CA-BSI with heparin-bonded and antibiotic-impregnated catheters, compared with standard CVCs [18], but no statistically significant benefit of antiseptic CVCs, coated with chlorhexidine and silver sulphadiazine (SS). However, none of the trials of antibiotic-impregnated CVCs were done in children. Two of the trials of heparin-bonded CVCs did involve children, but the study populations had unusually high infection rates, much higher than those currently seen with CVC bundles [19-21]. Head-to-head trials clearly showed that antibiotic-impregnated CVCs were more effective than chlorhexidine SS CVCs, but a head-to-head trial found that heparin-bonded CVCs were no more effective than chlorhexidine SS. There have been no head-to-head trials comparing antibiotic-impregnated with heparin-bonded CVCs.

The CATCH trial is funded by the UK National Institute for Health Research and is designed to inform policy decisions across the National Health Service about whether impregnated CVCs are effective and cost effective in the context of substantial improvements in CVC care. Antibiotic-impregnated and heparin-bonded CVCs are twice the cost of standard non-impregnated CVCs and there are concerns about serious adverse events, although heparininduced thrombocytopenia has never been reported to the manufacturer with the use of heparin-bonded CVCs. Antibiotic resistance has been reported in vitro with antibioticimpregnated CVCs and microbiologists are concerned about their widespread use. Moreover, current guidelines recommend their use only if CA-BSI rates remain high after implementation of CVC bundles [7, 10]. As a result, antibiotic-impregnated or heparin-bonded CVCs are used for only a small minority of children in PICU in the UK and USA (Miller and Mok, personal communication). On the other hand, we have learned that effective quality of care interventions need to be multifaceted [8]. The study by Rey et al. highlights one facet, the importance of total parenteral nutrition. We have yet to see whether the $\mathrm{CATCH}$ trial will add another-impregnated CVCs.

Conflict of interest The authors are involved in the CATCH trial to investigate the effectiveness of impregnated CVCs (trial number: ISRCTN34884569).

\section{References}

1. Institute of Healthcare Improvement (2007) Prevent central venous lineassociated bloodstream infections. http://www.ihi.org/IHI/Programs/ Campaign/CentralLineInfection.htm
2. Elliott TS (2007) An update on antimicrobial central venous catheters. J Hosp Infect 65(Suppl 2):34-38
3. Nosocomial infection national surveillance service (2010) Surveillance of hospital-acquired bacteraemia in English hospitals: 1997-2002. Health Protection Agency 
4. Slonin AD, Kurtines HC, Sprague BM, Singh N (2001) The costs associated with nosocomial bloodstream infections in the pediatric intensive care unit. Pediatr Crit Care Med 2:170-174

5. Miller MR, Griswold M, Harris JM, Yenokyan G, Huskins WC, Moss M, Rice TB, Ridling D, Campbell D, Margolis P, Muething S, Brilli RJ (2010) Decreasing PICU catheterassociated bloodstream infections: NACHRI's quality transformation efforts. Pediatrics 125:206-213

6. NPSA (2010) Matching Michigan. http://www.nrls.npsa.nhs.uk/ matchingmichigan/

7. Department of Health (2006) Saving lives: reducing infections, delivering clean and safe care. High impact intervention no 1 central venous catheter care bundle. Department of Health, London

8. Pronovost P, Needham D, Berenholtz S, Sinopoli D, Chu H, Cosgrove S, Sexton B, Hyzy R, Welsh R, Roth G, Bander J, Kepros J, Goeschel C (2006) An intervention to decrease catheter-related blood stream infections in the ICU. N Engl J Med 355:2725-2732

9. Bhutta A, Gilliam C, Honeycutt M, Schexnayder S, Green J, Moss M, Anand KJ (2007) Reduction of bloodstream infections associated with catheters in paediatric intensive care unit: stepwise approach. BMJ 334:362-365
10. Marschall J, Mermel LA, Classen D, Arias KM, Podgorny K, Anderson DJ, Burstin H, Calfee DP, Coffin SE, Dubberke ER, Fraser V, Gerding DN, Griffin FA, Gross P, Kaye KS, Klompas M, Lo E, Nicolle L, Pegues DA, Perl TM, Saint S, Salgado CD, Weinstein RA, Wise R, Yokoe DS (2008) Strategies to prevent central lineassociated bloodstream infections in acute care hospitals. Infect Control Hosp Epidemiol 29(Suppl 1):S22-S30

11. Pronovost PJ, Goeschel CA, Colantuoni E, Watson S, Lubomski LH, Berenholtz SM, Thompson DA, Sinopoli DJ, Cosgrove S, Sexton JB, Marsteller JA, Hyzy RC, Welsh R, Posa P, Schumacher K, Needham D (2010) Sustaining reductions in catheter related bloodstream infections in Michigan intensive care units: observational study. BMJ 340:c309

12. Rey C, Álvarez F, De-La-Rua V, Concha A, Medina A, Díaz J-J, Menéndez S, Los-Arcos M, Mayordomo-Colunga J (2011) Intervention to reduce catheter-related bloodstream infections in a paediatric intensive care unit. Intensive Care Med. doi:10.1007/s00134-011-2116-x

13. Singh-Naz N, Sprague BM, Patil S, Pollack MM (2000) Risk assessment and standardized nosocomial infection rate in critically ill children. Crit Care Med 28:2069-2075

14. de Jonge RCJ, Polderman KH, Gemke RJBJ (2005) Central venous catheter use in the pediatric patient: mechanical and infectious complications. Pediatr Crit Care Med 6:320-330

15. Merrer J, de Jonghe B, Golliot F, Lefrant J-Y, Raffy B, Barre E, Rigaud J-P, Casciani D, Misset B, Bosquet C, Outin H, Brun-Buisson C, Nitenberg G (2001) Complications of femoral and subclavian venous catheterization in critically ill patients. JAMA 286:700-707
16. Yogaraj JS, Elward AM, Fraser VJ (2002) Rate risk factors and outcomes of nosocomial primary bloodstream infection in pediatric intensive care unit patients. Pediatrics 110:481-485

17. Holmes A, Dore CJ, Saraswatula A, Bamford KB, Richards MS, Coello R, Modi N (2008) Risk factors and recommendations for rate stratification for surveillance of neonatal healthcareassociated bloodstream infection. J Hosp Infect 68:66-72

18. Gilbert RE, Harden M (2008) Effectiveness of impregnated central venous catheters for catheter related blood stream infection: a systemic review. Curr Opin Infect Dis 21:235-246

19. Anton N, Cox PN, Massicotte P, Chait P, Yasui Y, Dinyari PM, Marzinotto V, Mitchell LG (2009) Heparin-bonded central venous catheters do not reduce thrombosis in infants with congenital heart disease: a blinded randomized controlled trial. Pediatrics 123:453-458

20. Pierce CM, Wade A, Mok Q (2000) Heparin-bonded central venous lines reduce thrombotic and infective complications in critically ill children. Intensive Care Med 26:967-972

21. Chelliah A, Heydon KH, Zaoutis TE, Rettig SL, Dominguez TE, Lin R, Patil S, Feudtner C, St John KH, Bell LM, Coffin SE (2007) Observational trial of antibiotic-coated central venous catheters in critically ill pediatric patients. Pediatr Infect Dis J 26:816-820 